\title{
EL RETO DE EDUCAR EN TIEMPOS DE LA DIGITALIZACION DE LA VIDA: HACIA UNA PEDAGOGIA DE LAS RELACIONES ENTRE CUERPO, TEXTO Y TECNOLOGIA'
}

\section{THE CHALLENGE OF EDUCATING IN TIMES OF THE DIGITALIZATION OF LIFE: TOWARDS A PEDAGOGY OF RELATIONS BETWEEN BODY, TEXT AND TECHNOLOGY}

\section{Hernán Javier Riveros Solórzano ${ }^{1 *}$}

Universidad Distrital Francisco José de Caldas, Bogotá, Colombia.

\section{RESUMEN}

Este artículo se ocupa de presentar una propuesta educativa para el desarrollo del pensamiento crítico en relación con los procesos de avance de la biotecnología y la digitalización de la vida. Para cumplir con este propósito se toma como punto de partida la relación entre

(1) Este documento recoge algunos de los hallazgos propios de la tesis doctoral "Biopragmática: La cuestión de la vida en la relación cuerpo - texto - tecnología en algunas prácticas de producción de cuerpos por modificación de código genéticoalgorítmico. "realizada para el Doctorado en Estudios Sociales y el grupo de investigación Vivencias de la Universidad Distrital Francisco José de Caldas. El proceso investigativo fue financiado por el Centro de Investigaciones y Desarrollo Científico de la misma universidad, bajo el proyecto titulado: "Pensamiento crítico: cuerpos emergentes y territorializaciones de paz "

(1*) hriveros95@gmail.com Candidato a Doctor en Estudios Sociales. Magister en Comunicación - Educación. Especialista en Pedagogía de la Comunicación y Medios Interactivos. Licenciado en Lingüística y Literatura. Docente Investigador de la Facultad de Ciencias y Educación de la Universidad Distrital Francisco José de Caldas. Miembro de los grupos de investigación Vivencias y Educación, Comunicación y Cultura y de las redes internacionales: REDIPE, en la cual hace pate del Colectivo Iberoamericano de investigadores del lenguaje y la comunicación; OBITEL; ALFAMED y el GT CLACSO territorialidades, espiritualidades y cuerpos. Par evaluador e investigador asociado Minciencias Colombia. ORCID: https://orcid.org/0000-0002-1185-7603 Google Académico: https://scholar.google.com.co/citations?user=wFpF464AAAAJ\&hl=es 
cuerpo, texto y tecnología como un elemento de tipo estético y ético que permite comprender las diversas transformaciones de la existencia con el avance de diferentes herramientas en el ámbito de las tecnociencias y sus implicaciones en las transformaciones de la corporalidad y la subjetividad en su conexión con las condiciones sociales y culturales contemporáneas.

Así mismo, a partir de un marco teórico y un diseño metodológico sintonizados con los debates actuales en el campo de los estudios sociales, educativos y tecnológicos, el documento presenta las formas en las que sería factible consolidar acciones en el aula que permitan construir procesos pedagógicos, en clave de convergencia entre diversas disciplinas, para generar acciones educativas que respondan a las necesidades crítico - creativas de un contexto en el que la episteme de la vida como información exige de nuevas prácticas para pensar las formas de vivir y educar en una época de cambios y transformaciones como la contemporánea. Finalmente se presenta la biopragmática como posibilidad de trabajo educativo en el que se apuesta a una función crítica de la imaginación como elemento para proponer los procesos de apropiación de la existencia como obra de arte y del cuerpo como textualidad, los cuales son requeridos para asumir pedagógicamente un momento histórico transformado por condiciones como la aceleración del tiempo, la virtualidad del espacio y la racionalidad molecular propias del desarrollo de las tecnologías capaces de leer y modificar el código de la vida.

PALABRAS CLAVE: cambios tecnológicos, biotecnología, genética, lenguaje, pensamiento crítico, estética.

\section{ABSTRACT}

This article presents an educational proposal for the development of critical thinking about the processes of advancing biotechnology and the digitalization of life. To fulfill this purpose, the relationship between body, text and technology is worked as an aesthetic and ethical element that allows to understand the transformations of existence with the advancement of different tools in the field of technosciences and their implications in the transformations of corporality and subjectivity in its connection with contemporary social and cultural conditions. Likewise, based on a theoretical framework and methodological design tuned to the current debates in the field of social, educational and technological studies, the document presents the ways in which it would be feasible to consolidate actions in the classroom that allow the construction of pedagogical processes of convergence between different disciplines. This with the purpose of generating educational actions that respond to the critical - creative needs of a context in which the episteme of life as information requires new practices to think about ways of living and educating in a time of changes and transformations Finally, biopragmatics is presented as the possibility of educational work in which a critical function of the imagination as an element is proposed to propose the processes of appropriation of existence as a work of art and of the body as textuality, which are required to pedagogically address a historical moment transformed by conditions such as the acceleration of time, the virtuality of space and molecular rationality, which are a consequence of the development of technologies capable of reading and modifying the code of life.

KEYWORDS: technological changes, biotechnology, genetics, language, critical thinking, aesthetics.

\section{O DESAFIO DA EDUCAÇÃO EM TEMPOS DE DIGITALIZAÇÃO DA VIDA: RUMO A UMA PEDAGOGIA DE RELAÇÕES ENTRE CORPO, TEXTO E TECNOLOGIA}

\section{SUMÁRIO}


Este artigo apresenta uma proposta educacional para o desenvolvimento de um pensamento crítico sobre os processos de avanço da biotecnologia e a digitalização da vida. Para cumprir esse objetivo, a relação entre corpo, texto e tecnologia é trabalhada como um elemento estético e ético que permite entender as transformações da existência com o avanço de diferentes ferramentas no campo das tecnociências e suas implicações nas transformações de corporalidade e subjetividade em conexão com as condições sociais e culturais contemporâneas. Da mesma forma, com base em um referencial teórico e desenho metodológico sintonizado nos debates atuais no campo dos estudos sociais, educacionais e tecnológicos, o documento apresenta as formas pelas quais seria possível consolidar ações em sala de aula que permitam a construção de processos pedagógicos. convergência entre diferentes disciplinas. Isso com o objetivo de gerar ações educativas que respondam às necessidades crítico-criativas de um contexto em que a episteme da vida como informação requer novas práticas para pensar em modos de viver e educar em um momento de mudanças e transformações, como contemporâneo Por fim, a biopragmática é apresentada como uma possibilidade de trabalho educacional, em que uma função crítica da imaginação é ocupada como elemento para propor os processos de apropriação da existência como obra de arte e do corpo como textualidade, necessários para abordar pedagogicamente uma momento histórico transformado por condições como a aceleração do tempo, a virtualidade do espaço e a racionalidade molecular, consequência do desenvolvimento de tecnologias capazes de ler e modificar o código da vida.

PALAVRAS CHAVES: mudanças tecnológicas, biotecnologia, genética, linguagem, pensamento crítico, estética, ética, pedagogia.

\section{INTRODUCCIÓN: LA NECESIDAD DE ESTUDIAR LA DIGITALIZACIÓN DE LA VIDA EN TIEMPOS DE LA BIOTECNOLOGÍA}

El desarrollo de las tecnologías digitales y los diferentes cambios sociales y culturales asociados a sus avances, ha generado profundas transformaciones en las cotidianidades de los sujetos y las maneras en las que se entiende la sociedad, la educación y la vida. La decodificación del código genético, el diseño de nuevos algoritmos y su interacción con las decisiones de las personas, así como la configuración y crecimiento de lugares de sentido y existencia en Internet, junto con fenómenos como la aceleración del tiempo, la virtualización del espacio y la aparición de una racionalidad molecular, han cambiado el panorama investigativo de la contemporaneidad y llevado a nuevas problematizaciones que exigen un ejercicio analítico consecuente con las condiciones de una serie de cambios epistémicos ligados a la idea de la vida como información algorítmica y el cuerpo como textualidad genética editable. En esta medida, los escenarios educativos requieren del planteamiento de una serie de cambios, estrategias y posibilidades no solamente para identificar los nuevos contextos creados por fenómenos como el desarrollo de la Inteligencia Artificial, la biología sintética o el mejoramiento humano, sino también las posibilidades para desarrollar un pensamiento crítico capaz de comprenderlos y problematizarlos como parte de un proceso de construcción de subjetividades y ciudadanías en el ámbito escolar.

El siglo XXI está conectado profundamente con nuevos modos de pensamiento ligados a las transformaciones sociales y culturales propias de una modificación de las lógicas desde las que se concibe la realidad y en las que la racionalidad moderna, con su temporalidad lineal y su modelo industrial han dado paso a una concepción algorítmica de la vida y un sistema cultural caracterizado por la disolución 
de la densidad de lo que Lyotard (1986) llamó los relatos orientadores, la preponderancia de lo que Lipovetsky (2010) hizo visible como una especie de imperio del tiempo efímero y en general un sistema gobernado tanto por la imponencia del significante, al decir de Baudrillard (2009), como por la liquidez de la existencia en el marco de la vida de consumo signada por la inmediatez y lo intangible, como señalara Bauman (2009). Un panorama que ha generado diversas mutaciones en las que se ha hecho cada vez más evidente la forma en la que, "a medida que pierde fuerza la vieja lógica mecánica (cerrada y geométrica, progresiva y analógica) de las sociedades disciplinarias, emergen nuevas modalidades digitales (abiertas y fluidas, continuas y flexibles) que se dispersan aceleradamente por toda la sociedad" (Sibilia, 2010, p. 24). En otras palabras, se trata de un siglo en el que operan transformaciones constantes y dinámicas que se expresan en los desarrollos tecnológicos pero que, como, de acuerdo con Ong (2010), ocurre con toda tecnología, se corresponden directamente con los cambios de las consciencias, los ritmos y los modos de concebir la realidad por parte de las sociedades.

Las mutaciones de esta época, en consecuencia, pueden hacerse visibles al menos en tres niveles que terminan por conectarse definitivamente con los marcos propios de los desarrollos tecnológicos y que se ven reforzados con el avance constante de la digitalización: el tiempo, el espacio y la racionalidad. De este modo, en el caso de la temporalidad, la tecnología digital le ha permitido fluir hasta hacerse instantánea, ese denominado tiempo real en el que se hace visible la preponderancia del ahora; algo que, como lo han planteado diversos pensadores como Hard y Negri (2015) y Jameson (2000), se enlaza directamente con nuevos ritmos y lógicas de los sistemas económicos contemporáneos actuando sobre un vector temporal convertido en factor de rendimiento y productividad. Igual caso ocurre con el espacio, transformado por el desarrollo tecnológico hacia la virtualidad y la multiplicidad, de modo que hoy no existe una sola realidad, sino que han emergido diversas experiencias de lo real que no necesariamente se conectan con lo concreto sino que también dan cabida a otros lugares de sentido y acción, reduciendo las distancias físicas y generándose, con la tecnología móvil, una especie de sensación de ubicuidad. Y, finalmente, con la llegada de las tecnociencias $y$, particularmente lo que Rifkin (2009) denominó como el siglo de la Biotecnología, ha surgido una racionalidad distinta a nivel molecular, que ha cambiado radicalmente la comprensión de la existencia y el cuerpo al accederse tanto a la posibilidad de leer como de escribir en el código genético entendido como libro de la vida.

Estas tres condiciones se pueden evidenciar más allá del nivel abstracto y conceptual, en las formas en las que se configuran las prácticas de los sujetos hoy y sus modos de vivir, pensar y actuar en la multidimensionalidad de las sociedades contemporáneas. De este modo, la transformación del tiempo se hace visible con la presencia de tecnologías cada vez más instantáneas que ya no solamente se erigen como elementos exteriores de los sujetos, sino que se insertan en cada dimensión de su actuar diario, de manera que marcan los ritmos de su día a día. El tiempo acelerado, como en su momento lo advirtiera Paz (1985), se llena entonces tanto de la demanda de inmediatez como de la sobreabundancia de tareas, de modo que no se trata del hecho de que los minutos corran más rápido sino de la presencia de una mayor cantidad de asuntos por cumplir, en conexión con una lógica de la fugacidad y el imperativo según el cual el futuro no está en el horizonte del porvenir, sino en un presente de corta duración, en el que se precisa actuar en función del ahora y el ritmo inmediato de la aceleración de las redes. Una temporalidad que con las tecnologías se ha hecho presente en el 
universo de lo cotidiano, en la angustia ante la no respuesta inmediata al correo electrónico o al mensaje de Whatsapp y en la necesidad de procesar la información al mismo ritmo que los ordenadores y las exigencias de un sistema para el que no hay espera ni pausas sino un eterno fluir del instante.

En el caso del espacio, el desarrollo tecnológico le ha permitido también transformarse en las vidas cotidianas de los sujetos como sucede con la temporalidad. Si hoy se vive con la flexibilidad del tiempo real, también se ha logrado superar las fronteras espaciales y concebir una virtualidad que se constituye en ruptura de los lindes de la imaginación. Ya no solo se sueña con lo virtual, sino que se habita en esos mundos posibles que antes solamente eran parte del universo de las fabulaciones. $Y$, al mismo tiempo, la potencia tecnológica hace factible estar en varios lugares simultáneamente, convirtiendo a la espacialidad en una cuestión de significación, de presencialidad mediada por las maneras en las que las conexiones con un lugar, por más distante que sea en lo concreto, le dan condición de realidad en el nivel de las emociones y los afectos. El espacio, de este modo, se ha vuelto infinito y abierto, multidimensional y sin límites. Las cámaras, los dispositivos, la telefonía móvil y la conexión a la red hacen factible habitar varios lugares al mismo tiempo y desarrollar relaciones muy profundas con escenarios en los que, más que con presencialidad física, es posible estar como avatar, perfil o una serie de significaciones construidas sobre sistemas de post, mensajes y contenidos en los que el sujeto fluye con la velocidad de la red pero también con una concepción de espacio que transforma sus modos de vivir y entender lo real como territorios de sentido.

Pero si el tiempo se ha acelerado y el espacio se ha expandido y contraído en su virtualidad y ubicuidad, el desarrollo tecnológico ha logrado transformar más profundamente lo que se entiende por la vida en sí al intervenirla con el desarrollo de los procesos de digitalización que ya no solo operan sobre los datos de los sujetos puestos en máquinas y dispositivos desde su exterioridad, sino al adentrarse en la posibilidad de hacer visible la naturaleza de la corporalidad y de la vida como un código textual y matemático. $Y$ no se trata solamente de la actual revolución algorítmica y sus múltiples implicaciones en las decisiones que toman los sujetos a través de las interacciones con diferentes software, herramientas y sistemas de programación, sino de las maneras en las que el desarrollo de tecnociencias como la biotecnología, la nanotecnología, las tecnologías de la información y las ciencias cognitivas han cambiado el panorama de lo que se entiende por vida y corporalidad al situarse en el plano de lo molecular. Una serie de avances que han modificado la racionalidad y la episteme contemporáneas, al hacer posible no solo el paso de un modelo mecánico y maquínico a uno informacional y relacional en relación con la existencia, sino la aparición de nuevos escenarios para pensar la subjetividad y la sociedad en ese sí mismo biológico que emerge con el avance en el conocimiento del genoma, las estructuras de la mente y las posibilidades para emular o mejorar la condición humana en campos como la biología sintética y la ingeniería genética, entre otros.

Se trata en consecuencia de una revolución digital de la concepción de la vida misma, nacida en el seno de su posibilidad de ser intervenida mediante el conocimiento del código genético y su digitalización. De manera que las tecnologías digitales de hoy se mueven, además de las pantallas y sus estímulos en el día a día, en el interior de las corporalidades y en los intersticios de la relación entre naturaleza y cultura, toda vez que, en los tiempos actuales, "el laboratorio se ha convertido en una especie de fábrica abocada a crear nuevas formas de vida molecular. $Y$ en esa creación, también se fabrica un nuevo modo de entender la vida en 
sí" (Rose, 2012,p.42). Dicho de otro modo, en el momento en el que las tecnologías digitales han pasado a decodificar la constitución de la existencia, no solamente se ha concebido un avance que cambia el panorama de las ciencias y las posibilidades de desarrollo tecnológico, sino que, en esencia, opera un giro epistémico, el de "la nueva episteme anclada en la vida como información” (Rodríguez, 2017, p. 99) y cuyos efectos operan tanto en la racionalidad científica como en las maneras en las que se generan los procesos sociales, culturales y educativos, puesto que la vida es ahora susceptible de leerse, interpretarse y escribirse al convertirse en un lenguaje signado por el descubrimiento del genoma y el avance de técnicas para su edición, desde la algenia hasta el actual avance en CRISPR ${ }^{2}$.

Ahora bien, la modificación epistémica en relación con el concepto de la vida también se moviliza hacia la transformación de lo que se entiende por humanidad y por cuerpo. Esto pues, más allá del debate filosófico entre el humanismo, el posthumanismo y el transhumanismo, puesto en movimiento por la aparición de sujetos modificados tecnológicamente y las experimentaciones en hibridaciones y quimeras, lo que revela una época de desarrollo y avance como la que se tiene en este momento histórico, es justamente la potencia para que sea factible generar nuevas condiciones para las corporalidades, las subjetividades y la

$2 \quad$ CRISPR se refiere a una serie de tecnologías y procesos usados en la edición genética. El acrónimo se refiere, en inglés, a Clustered Regularly Interspaced Short Palindromic Repeats, lo que en español traduce como Repeticiones Palindrómicas Cortas Agrupadas y Regularmente Espaciadas, fenómeno que se da en algunas bacterias. $A$ partir de ello, con la intervención de Cas9, una endonucleasa que actúa como una especie de "tijera molecular", se hace posible realizar cortes precisos en $A D N$ con la guía del ARN, el cual dirige a la tijera para llevar a cabo el corte y posibilitar que se añadan nuevas secuencias de ADN. La técnica fue trabajada por científicas como Emanuelle Charpentier y Jennifer Doudna, revelándose como uno de los sistemas mas avanzados de edición genética, aunque no exento de polémica por su carácter experimental y más recientemente su uso en el caso de las bebés modificadas genéticamente por el científico chino He Jiankui para hacerlas inmunes al VIH y que le valieron una pena de prisión por actuar fuera de los límites de la bioética y la medicina. naturaleza humana, todas ellas alteradas por las posibilidades de modificación surgidas con el desarrollo tecnocientífico. De esta manera, si "la biotecnología nos permite alterar la naturaleza humana y por tanto la idea de lo que es ser humano" (López-Pellisa, 2015, p. 151), es necesario situar la temática de las discusiones más allá de cualquier postura tecnófila o tecnófoba, ante una serie de cambios que demandan de un pensamiento crítico capaz de dar cuenta tanto de las conexiones entre las mutaciones sociales del tiempo, el espacio y la episteme con las cotidianidades de los sujetos, como de las posibilidades de plantear procesos educativos en los distintos escenarios escolares y culturales que aparecen con una dinámica de la existencia que se mueve entre la digitalización en las pantallas y la molecularización de la existencia.

La humanidad, así pues, ha pasado de entenderse en una relación de distancia frente al universo tecnológico a comprenderse en una necesaria interconexión. Esto puesto que el desarrollo de tecnologías de la vida en el orden molecular $y$, al mismo tiempo, el mejoramiento en los trabajos de desarrollo de ciencias como la biónica, la cibernética y la microelectrónica, han permitido generar nuevos territorios de interacción entre los sujetos y los dispositivos tecnológicos que van más allá del uso de dispositivos, redes y pantallas, a gestar una especie de relación orgánica con la digitalización. De este modo, lo humano hoy se ha movido de los límites y las fronteras de la biología clásica, a una concepción móvil posibilitada por los descubrimientos y avances de las tecnologías moleculares y digitales, en las que los nuevos horizontes biológicos se trazan desde las posibilidades de acción y creación en los laboratorios en los que se desarrollan tecnociencias para las que cuestiones como el ADN no son barreras, sino puntos de partida. El ser humano, en consecuencia, ya no es una entidad plenamente definida y condicionada por 
su anatomía, sino una composición compleja de relaciones e interconexiones entre su carácter textual biológico, químico y fisiológico y las textualidades igualmente complejas de la cultura, la sociedad y el universo siempre creciente y en expansión de las tecnologías, todo ello posibilitado por la transformación epistémica de la concepción de la vida como información gestada por el desarrollo de la edición genética y la digitalización de los códigos más profundos de lo que constituye a la misma humanidad.

Y es allí donde, si es el código genético el que marca una transformación significativa de la naturaleza y definición de humano, es su carácter digitalizable y editable el que permite pensar la forma en la que, en la constitución textual a nivel genético de la humanidad, el cuerpo y el lenguaje juegan un papel decisivo y fundamental. Esto porque, como ya se ha señalado, la problematización no sería un mero asunto de definiciones, sino que como implica el debate entre lo posthumano, lo transhumano y lo humano y que ha dado para reflexiones conceptuales y filosóficas por parte de autores como Braidotti (2015), Ferry (2017), Diéguez (2017) Aguilar (2008) y otros, la cuestión problemática radica en el hecho de que si la concepción de humanidad ha cambiado, también lo han hecho toda una serie de nociones y prácticas asociadas a ello, lo que genera un interesante panorama para el estudio crítico de la sociedad contemporánea, atravesada por esa intrincada red de signos, cifras y códigos que la digitalización ha puesto sobre la vida con la expansión de la biotecnología y que se ha expresado en una corporalidad entendida como textualidad y un sistema de signos que se expande al interior de la constitución de los cuerpos, toda vez que:

la aparición de este nuevo paradigma científico y el establecimiento de un mapa genético... marca la transición entre una concepción del cuerpo entendido como unidad anatómica... a otra en la que el cuerpo es fruto de la combinación de piezas de significado (genes). (López del Rincón, 2015, p. 225)

La digitalización de la vida, expresada en una transformación de la concepción de lo humano y materializada en un cambio de la idea de cuerpo, se revela como una cuestión de lenguaje, es decir, de significación antes que de técnica y, como lo han planteado diversas corrientes teóricas, su análisis no puede limitarse al asombro ante la potencia de los procesos tecnocientíficos, sino empezar a mirar profundamente los orígenes y fundamentos desde los que se gestan las modificaciones en ese sistema de signos que es el código genético. Por ello el reto para el estudio de las sociedades y para el trabajo educativo no puede estar en un inventario de las modificaciones tecnológicas que son posibles con la edición genética o la reflexión en abstracto sobre las implicaciones éticas y conceptuales del cambio de época con la llegada de las terapias genómicas o la modificación de ADN precisa con CRISPR, sino en la revisión sistemática de las concepciones y prácticas que se movilizan entre y tras estos cambios, esto es, entender que sí, con la transformación epistemológica contemporánea, "nuestra estructura molecular se constituye en un código escrito" (Aguilar, 2008, p. 27), la tarea desde su análisis en tanto que lenguajes es dar cuenta de las estructuras profundas que movilizan los códigos y las acciones educativas para responder a un contexto en el que todo lo que concebimos y entendemos se ha movido hacia un universo de signos en rotación, códigos y datos en los que se asoma la naturaleza constitutiva de la existencia.

De este modo, entonces, el trabajo analítico evidencia la complejidad de un ejercicio investigativo y crítico en el que las fronteras disciplinares se difuminan y que requiere que, del mismo modo en el que se transforman los conceptos de cuerpo, humanidad y vida con el 
desarrollo de una digitalización que ha gestado un profundo cambio epistémico, también se generen nuevas metodologías y formas de abordar las nuevas problematizaciones que surgen con el avance de las tecnociencias y el reto que implica entender la corporalidad como textualidad y la tecnología como un factor que ya no es ajeno a los sujetos sino que es susceptible de constituirlos desde su dimensión molecular. Una exigencia en la que es completamente claro que en tanto que la actual perspectiva epistemológica expresa que, al ser lenguaje, "los organismos son algoritmos" (Harari, 2017, p. 350 ) y ellos son susceptibles de modificación, es necesario consolidar estrategias metodológicas que permitan asumir el reto de la digitalización de la vida, la textualidad de los cuerpos y la transformación de lo humano como parte de las discusiones acerca de la sociedad y puntos de reflexión para los entornos educativos con el propósito de gestar esas posibilidades de empoderamiento, conocimiento y cuidado de sí necesarios para la consolidación de esas nuevas ciudadanías en tiempos de avance de la capacidad e impacto de la biotecnología.

Una necesidad que se hace mucho más urgente cuando se tiene en cuenta la tremenda responsabilidad de la academia y la educación ante una serie de avances tecnológicos que puede fácilmente superar los límites de la reflexión y las estrategias pedagógicas y didácticas disponibles tanto por la tendencia a veces dominante a reducir el universo de la tecnología a un plano instrumental como las innegables conexiones entre los procesos de innovación científica y las relaciones de poder inherentes a todo avance tecnológico. Es necesario, en consecuencia, que los trabajos analíticos y críticos se sintonicen con el cambio epistemológico resultante del desarrollo de las tecnociencias $y$ sus transformaciones conceptuales, pero también que la mirada reflexiva permita dar cuenta del necesario compromiso ético que ha de tejerse desde los escenarios educativos ante las implicaciones sociales y culturales resultantes de la digitalización de la existencia. Un reto que, en el orden del lenguaje, se convierte también en un ejercicio estético, en tanto que, si los cuerpos son textualidades, la apuesta sería no permitirles ser meramente códigos que atrapan la vida al diseñarla, sino llevarles a ser poesía capaz de leer esa compleja realidad que se revela en la interacción entre las corporalidades, los genes y las tecnologías en el nivel molecular. Una problematización que se hace visible en una pregunta esencial: ¿cómo construir elementos para el análisis crítico y la consolidación de procesos educativos en el contexto de los desarrollos de la biotecnología y los retos que emergen a partir de la transformación de la vida entendida como información, a causa del avance de la digitalización de la existencia como consecuencia del desarrollo de las tecnociencias contemporáneas?, la cual es el punto de partida para la investigación recogida en este artículo.

Este documento se ocupa, en consecuencia, de presentar una apuesta crítica, surgida como resultado de una investigación doctoral, para enfrentar los retos y problematizaciones que surgen para los estudios sociales y la educación a partir de la digitalización de la vida causada por el desarrollo biotecnológico y la transformación producida sobre los conceptos de corporalidad, humanidad y subjetividad. Se trata, en esta medida, de un recorrido por una perspectiva conceptual y metodológica que plantea las nociones y practicas en las que se hace visible el impacto y campos de trabajo de la modificación del código genético, para luego, desde la relación entre cuerpo, texto y tecnología, generar las condiciones para leer los contextos contemporáneos $\mathrm{y}$, al mismo tiempo potenciar procesos reflexivos en los escenarios escolares a partir de la interacción entre ciencia, ética y estética, toda vez que, como se revelará en el análisis, ante las contradicciones y paradojas propias de la actual relación entre tecnología y 
sociedad, es el arte el que tiene la posibilidad de gestar las interacciones, conexiones y reflexiones que permitan convertir la existencia en una obra de arte a partir de su naturaleza textual. Finalmente, a partir de la formulación de una serie de estrategias y posibilidades pedagógicas discutidas con un colectivo de docentes en la ciudad de Cajamarca, en Perú ${ }^{3}$, el documento concluye con el planteamiento de esa posible ruta de trabajo de tipo biopragmático que permitiría llevar al escenario escolar latinoamericano la discusión acerca del universo biotecnológico a través del impulso del pensamiento crítico y el desencadenamiento de la imaginación como elementos para problematizar qué es eso que se entiende por lo humano, el cuerpo y la existencia en tiempos de la digitalización de la vida.

\section{EL CÓDIGO GENÉTICO: ESPACIO PARA LA CIENCIA, LOS ESTUDIOS SOCIALES, EL ARTE Y LA EDUCACIÓN EN LA RELACIÓN CUERPO - TEXTO - TECNOLOGÍA}

El giro epistemológico generado por el cambio de paradigma implícito en la modificación de la concepción de la vida hacia una comprensión de la misma como información, sumado al desarrollo de una serie de nuevas tecnologías cada vez más conectadas con la interioridad de los sujetos y diseñadas en una dinámica molecular, ofrecen la necesidad de una transformación profunda en relación con los conceptos desde los cuales se entiende la tecnología, la corporalidad y la existencia. Una modificación que no solamente se expresa, como ya se ha visto, con la aparición de una relación con la textualidad a nivel de los cuerpos y los sujetos, sino ante todo, con la construcción de nuevos marcos teóricos y metodológicos que puedan sintonizarse con las maneras en

3 En el proceso de desarrollo de la investigación se llevaron a cabo una serie de encuentros entre el 12 y el 14 de octubre de 2018 en la ciudad de Cajamarca, Perú, en el marco de un seminario internacional con la Dirección Regional de Educación de dicha región, en los que se exploraron posibilidades de uso y apropiación de la relación cuerpo - texto - tecnología en diferentes entornos escolares. las que los planos políticos, éticos, sociales y culturales se han movido a los escenarios de la edición genética y la intervención directa sobre la vida en toda su complejidad.

Esto se hace mucho más claro cuando se observa la contundencia de aquello sobre lo que se habla cuando se trabaja en los procesos de la actual digitalización de la vida y los alcances y potencia del desarrollo con el que se cuenta en los espacios de experimentación contemporánea. Hoy, no solamente se ha logrado llevar a cabo la realización de algunos elementos anunciados por la ciencia ficción en su momento, sino que se han consolidado toda una serie de movimientos y desarrollos en diversos campos en los que se han materializado diversos espacios de modificación de la existencia tanto en el ámbito de lo biológico como en lo estético, lo político y lo cultural. Este es el caso de la presencia contemporánea de semillas transgénicas (que han sido objeto de álgidos debates en diversos escenarios sociales), pero también de la investigación en vida e inteligencia artificial, así como desarrollos en la producción de órganos sintéticos, los avances en redes neuronales, robótica y la construcción en laboratorios y fuera de ellos de hibridaciones como las quimeras cerdo-mono anunciadas a finales de 2019, nuevas formas de vida como Edunia (plantimal elaborado por el artista Eduardo Kac con su propio ADN y el de la petunia) y las diversas intervenciones que biohackers, grinders y cyborgs ${ }^{4}$ hacen sobre sus cuerpos al

4 En las sociedades contemporáneas, con el avance de diversas tecnologías, se ha hecho posible que se generen diversos movimientos en los que se trabaja la intervención sobre el cuerpo a partir del uso de diferentes tecnologías. Esto ha llevado a que existan cyborgs, esto es, sujetos con modificaciones y máquinas insertadas en sus cuerpos, pero también biohackers, quienes se ocupan de trabajar en el manejo y gestión de la propia biología mediante diversas técnicas que, en el caso de los grinders, se ubica en el manejo de inserción de máquinas y chips bajo la piel, pero también de procesos iniciales de edición genética. El biohacker, adicionalmente, practica la biología DIY (hagalo usted mismo), lo que se convierte también en una apuesta crítica frente al esquema científico tradicional y que implica que las intervenciones pueden hacerse fuera del entorno de los laboratorios, incluso en garajes y otros espacios no nec- 
convertirlos en terrenos para la experimentación con genes, máquinas e implantes que modifican la corporalidad. Así, es posible encontrar hoy sujetos como Neil Harbisson, quien posee una antena en su cabeza que le permite escuchar el color, pero también como Tim Cannon o Lepth Anonym, quienes se insertan diversos elementos y maquinas bajo la piel, y al mismo tiempo variedades de animales modificados genéticamente para ser luminiscentes 0 , en el caso de algunas empresas biotecnológicas, servir como estrategia para controles de plagas o procesos de agricultura altamente tecnificada.

Pero el panorama inquietante no solo es visible en los diferentes experimentos que son materia de discusión pública o que protagonizan álgidos debates en campos del saber como la bioética o la biojurídica. También aparecen incluso al interior de los desarrolladores de las tecnologías avanzadas, para quienes es este el momento histórico para iniciar una discusión seria y argumentada acerca de los procesos de edición genética y de la digitalización de la vida, para lo cual se hace preciso contar con marcos teóricos y metodológicos que puedan ser usados en diferentes escenarios como el científico, el social, el cultural y el educativo. Esto pues los procesos tecnológicos con el código genético no se limitan únicamente al manejo de herramientas avanzadas sino que involucran una experimentación cuyas implicaciones van más allá de cualquier otra tecnología durante la historia, dado que lo que se controla es la vida misma y la naturaleza de los organismos, tal como lo refiere una de las inventoras de la aplicación de la tecnología CRISPR-Cas9 para la edición de genes, Jennifer Doudna junto al investigador Samuel Sternberg (2018):

gene editing technology gives us the chance to hold an informed public discussion about how we want to use CRISPR's most far reaching power: the ability to control the

esariamente ligados a la tradición científica. En la mayoría de los casos, los grinders son a su vez biohackers y cyborgs. future of life. But if we wait too long, we may find that the reins have slipped from our hands (p. 239)

Así,enelprocesoactualdedesarrollotecnológico, no solo hay un cambio epistémico, sino que el trabajo en el código genético ha abierto un nuevo campo de posibilidades de reflexión y de crítica, pero también de opciones educativas en las que ya no se puede comprender la cuestión del ADN como un dominio exclusivamente las ciencias naturales, la química o la biología, sino como un asunto interdisciplinar, dado que si "la manipulación de los genomas ... abre las puertas a una tecnología mucho más potente. Lo que está en juego ya no es una célula, sino un organismo: nosotros mismos" (Mukherjee, 2017, p. 556), entonces la discusión acerca de las relaciones entre los cuerpos, la humanidad, la vida y las tecnologías no puede limitarse a formulas y ecuaciones, sino que tiene que moverse al terreno político, al análisis del problema del lenguaje y sobre todo a esos procesos de formación de ciudadanía que son requeridos para enfrentar problematizaciones como las que se encuentran tras el código de la existencia y que van más allá de conocer una serie de descubrimientos y experimentos con los saberes genéticos o algorítmicos, en la posibilidad de analizar los modos en los que los procesos científicos y tecnológicos entran en conexión con profundos cambios culturales, sociales e incluso políticos y económicos relacionados con la actual capacidad para comprender y reconfigurar los cuerpos y las vidas con el uso de la digitalización.

En este sentido, en términos de un marco teórico para asumir los retos que presenta un contexto atravesado por el código genético como elemento fundamental de reflexión en conexión con la tecnología, se hace necesario pensar en una relación de vital importancia para hacer visibles las diversas conexiones que se encuentran ligadas a la vida digitalizada 
y que es justamente la que se entreteje entre cuerpo, texto y tecnología. Al entenderse que las corporalidades hoy, como la vida, están compuestos por una serie de códigos editables, esto es, una textualidad algorítmica que es al mismo tiempo información e interacción en la que los signos de la existencia se encuentran en constante movimiento y conexión con elementos biológicos, sociales y culturales; se abre la puerta a la comprensión de una visión de la genética que no está únicamente relacionada con un sistema de cifras combinables a nivel digital, sino mejor, en una perspectiva que escapa de cierto determinismo informacional para situarse en un modelo interactivo del cuerpo como texto. Dicho de otra manera, la corporalidad no se puede entender únicamente reducida a una cierta preponderancia del código genético en tanto que estructura molecular, sino que por el contrario debe revisarse en esa relación interactiva que se construye con los significados, sentidos y tejidos de la sociedad y la cultura, los cuales también se integran en ese conglomerado de datos que es el ser y su organismo y que hoy, no puede dejarse distanciado de la tecnología que no solamente permite editar el ADN sino también configurar condiciones que modifican las vidas de los sujetos a todo nivel.

Para desentrañar estas relaciones, es preciso volver sobre una serie de cuestiones que ya han sido previamente esbozadas pero que resultan necesarias para configurar una serie de conceptos que pueden ser útiles para asumir crítica y educativamente las implicaciones de estudiar el código genético en tiempos de la digitalización de la vida. Lo primero es la transformación del tiempo y el espacio que emergen con las tecnologías digitales y que, con el desarrollo de las tecnociencias, empiezan a situarse en el plano molecular de la existencia. Como se dijo en su momento, la época actual está dominada por una concepción de tiempo ligada a lo efímero y la instantaneidad pero, curiosamente, en el nivel de desarrollo de tecnologías genéticas, los experimentos y trabajos, como lo plantea Rose (2017) no solo esbozan una nueva dimensión de la biopolítica sino que hacen visible como ella misma "está imbuida en el porvenir: la preocupación acerca del futuro y el interés en traer ese futuro al presente y gobernarlo en nombre del futuro" (p.33). En otras palabras, un ahora que se gesta pensando en el mañana pero que al mismo tiempo se ve delineado por la velocidad de los avances y la multiplicación de las necesidades, puesto que, como lo recuerdan Doudna y Sternberg (2018), "every time we unlock one of nature's secrets, it signals the end of one experiment - and the beginning of many others" (Doudna y Sternberg, 2018, p. 246). La tecnología avanza constantemente y, junto con el flujo dinámico del tiempo acelerado va generando nuevos cuestionamientos y retos que es preciso empezar a integrar tanto en las miradas propias de la ciencia y la tecnología como en la discusión de los estudios sociales y también en la reflexiones en el campo educativo.

En cuanto a la cuestión del espacio, el desarrollo de la investigación en el código genético ha generado un reto al encontrar un nuevo lugar para el desarrollo y constitución de lo humano y, en términos de lenguaje, un escenario interesante para la construcción de los procesos de sentido y de relación entre los signos. EI ADN, como lo ha demostrado la biosemiótica, en estudios como los de Hoffmeyer (2008), adquiere un valor sígnico cuando se trata de organismos y, como lo ha tratado la bioinformática, tal cual lo ilustra Roldán (2015) se convierte en un elementos con el que es posible tanto gestar las condiciones para la vida y la inteligencia artificial por procesos de emulación usados en la escritura de bases de datos genómica, biológicas y algoritmos genéticos, como ofrecer los principios para el mejoramiento y modificación de los cuerpos humanos, animales y vegetales. El libro de la vida ya no es un concepto abstracto, sino que es ese 
territorio molecular en el que es posible escribir y configurar no solo la corporalidad entendida como un elemento mecánico o material, sino desde esa interioridad que son sus códigos encontrar el camino para modificaciones cada vez más profundas puesto que las tecnologías contemporáneas, "promise to revolutionize our understanding of how different combinations of genes interact to cause disease and determine how we look, act and think" (Piore, 2017, p. 72).

Ahora bien, ante tales transformaciones es que la ciencia, los estudios sociales y la educación definitivamente se encuentran frente a uno de sus principales desafíos: el de generar condiciones para la comprensión, análisis y fundamentación de un pensamiento crítico consecuente con cada descubrimiento pero también capaz de suscitar nuevas discusiones y procesos reflexivos. En ello, el arte ha jugado, como en otros momentos de la historia un papel fundamental, en tanto que ha sido justamente el trabajo de los artistas en el ámbito biotecnológico lo que ha permitido generar las polémicas y las reflexiones sobre la textualidad molecular de los cuerpos y las maneras en las que la tecnología contemporánea no solo ha procedido con transformaciones epistemológicas, sino también profundos giros ontológicos en los que se han logrado derruir dualismos clásicos como el de naturaleza / cultura o el de sujeto / objeto. El bioarte $\mathrm{y}$, particularmente apuestas como el arte transgénico de Eduardo Kac, ha permitido encontrar las posibilidades para hacer de la obra un espacio reflexivo, en el que la producción estética implica una "nueva dimensión pragmática y simbólica del arte como la creación literal de la vida y la responsabilidad literal hacia la vida" (Kac, 2010, p. 373). En otras palabras, el bioarte ha abierto el camino para pensar más allá de la instrumentalización de la tecnología que hace posible digitalizar y modificar la vida en la consolidación de acciones reflexivas que abarquen no solo la ciencia sino también los estudios de la sociedad, la cultura y la educación en las sociedades contemporáneas.

Para analizar más detalladamente esta cuestión, puede ponerse por caso dos de las muestras más representativas de la obra de Kac: la ya cita Edunia, del 2008 y la instalación denominada El octavo día, del 2001. La primera es una planta que combina el ADN del artista con el de la petunia, lo que le permite contar con una tonalidad rojiza que colorea las venas que se materializan en sus flores; $y$ la segunda consiste en una cúpula en la que se encuentran diversas criaturas trangénicas que poseen un gen que contiene el código PFV (Proteína Fluorescente Verde), lo que les da luminiscencia y que a su vez interactúan con un biobot (un robot que se impulsa por una colonia de amebas). En ambos casos, el arte logra llevar a efecto práctico los desarrollos científicos, incluso años antes de ponerse en operación, pues vale la pena señalar que anterior al lanzamiento de biobots a finales de 2019 e inicios de 2020 , ya se había anunciado el concepto por parte del artista. Pero no solamente se queda en la producción de una serie de criaturas, sino que dinamiza las maneras en las que se entiende la relación entre sujeto y objeto, pues sus obras pasan a adquirir un cierto grado de subjetividad ya que no son materia inerte, sino nuevas formas de existencia en las que naturaleza y cultura encuentran su continuum y síntesis en la vida construida al poner en interacción el ADN dispuesto por lo natural con el desarrollo tecnológico gestionado por el universo cultural. $\mathrm{Y}$, al mismo tiempo hace visible la necesidad de enfrentar las cajas negras de la biotecnología, como lo habían propuesto en el terreno teórico los estudios de ciencia, tecnología y sociedad desarrollados por Latour (1987), y Domenech y Tirado (1998) y la perspectiva analítica de López del Rincón (2015), de manera que la presencia de la obra artística logre sacar a flote esas discusiones aplazadas pero necesarias para cuestionar los avances del desarrollo tecnológico y los límites que a veces 
se extienden más allá de los alcances de las reflexiones de las múltiples ciencias bio.

El arte así invita a la reflexión, a una forma de la crítica que, como los avances de la tecnología, se constituye desde los límites, las rupturas y los intersticios. Esto pues una vez se ha digitalizado el código genético no solamente la vida se revela como información, sino que es posible, como lo ha señalado el mismo Kac (2010), al lado de redefinir lo que se entiende por naturaleza, encontrar en el código genético no una frontera, sino un punto de partida. $Y$ he ahí la exigencia conceptual a los estudios sociales, la ciencia y la educación, en cómo pensarse esos espacios para analizar la digitalización de la vida, desde qué marcos teóricos, con cuáles conceptos y bajo qué precisiones y precauciones metodológicas, pues, con la aparición de una nueva conceptualización de la existencia, unas maneras distintas de pensar lo humano y una innegable realidad textual de la corporalidad, "los límites de los cuerpos deben convertirse en objeto de discusiones colectivas ... ahora tenemos que aprender a pensar diferentemente en nosotros mismos y a experimentar nuevos modos de pensamiento" (Braidotti, 2015, p.232). Los marcos teóricos y metodologías deben entonces replantearse desde el marco de las nuevas epistemes y ontologías que surgen con el desarrollo de las tecnologías y los códigos genéticos $y$, al encontrarse con el universo de la ciencia, los estudios sociales y la educación, generar las condiciones para el análisis y la consolidación de esos pensamientos críticos necesarios para la era de la biotecnología.

La propuesta de trabajo que se consolidó para la investigación que fundamenta este artículo se basó, en consecuencia, en el planteamiento de una propuesta emergente, de convergencia e interacción conceptual y metódica tanto para el campo de los estudios sociales como para el ámbito educativo a partir de dos cuestiones fundamentales: el reconocimiento del cuerpo como texto como base ontológica y la perspectiva del pensamiento crítico como actitud límite e interacción ente estética y ética como elemento fundamental para los procesos analíticos y de reflexión a nivel escolar. En la primera de las dimensiones, se plantea una visión de lenguaje en la que el elemento fundamental es la práctica por encima de los procesos de semiosis implicados en la concepción del código genético como signo, lo que remite a una preocupación por un aspecto pragmático en la textualidad de los cuerpos. Por su parte, en la segunda, se entiende al escenario educativo como un espacio para la construcción de la crítica a partir de la fortaleza de la posibilidad creativa e imaginativa, susceptible de pensar problematizaciones nuevas y gestar ese nuevo espíritu científico que, como planteó en su momento Bachelard (1974) apunta más a las preguntas que a las respuestas.

Se formula entonces como concepto la idea de una Biopragmática, esto es, una manera de entender los signos de la vida digitalizada como signos en acción que escapan de los límites de la semiosis o de la dictadura del algoritmo informático y que remiten no solo a un proceso de significación que emerge de las relaciones de signo a signo, sino también de las maneras en las que el código genético se conecta con la cultura, la historia y la sociedad. Para la biopragmática, la vida es interacción, acción en movimiento y agenciamiento y, por tanto, el problema no radica en su modificación técnica o en la potencia escritural de la biotecnología, sino en las condiciones para construir otras maneras de vivir desde un conocimiento de sí que sea a la vez cuidado de sí y cuidado de los otros. La vida, en consecuencia, es obra artística que se construye desde el saber y la apropiación de los códigos y, donde, como lo planteasen Hardt y Negri (2015), la corporalidad no es mera técnica, sino que "el nuevo cuerpo debe ser capaz de crear una nueva vida.. un cuerpo potente producido por la más elevada conciencia” (p.238), y ella 
no emerge sino de una relación crítica ente estética y ética, esto es, en la posibilidad de crear desde las texturas de la imaginación y la responsabilidad del artista que ha convertido en arte su propia existencia. La vida, en esta medida, es información algorítmica pero no por ello se encuentra contenida bajo una especie de supremacía tecnológica, sino que se libera al ser analizada, experimentada y apropiada por los sujetos, factor en el que tanto el ámbito de las ciencias naturales como de los estudios sociales exigen de puntos de convergencia que son susceptibles de consolidarse en el ámbito de la educación entendida desde la praxis de la formación para la crítica y la creación.

Ahora bien, conceptualmente hablando, esta visión de la vida como práctica y agenciamiento que se liga con la concepción del cuerpo como textualidad y la tecnología como elemento que moviliza agenciamientos profundamente conectados con los sentidos profundos de la sociedad y la cultura, encuentra conexiones directas con la tradición crítica que subyace a los estudios de Spinoza (2015), Deleuze y Guattari (2015), Hardt y Negri (2015), Esposito (2011), Sibilia (2010), Braidotti (2015), Agamben (2017) y en general toda una serie de teóricos que han permitido no solamente preguntarse acerca de la potencia de los cuerpos sino también de los modos en los que hoy la vida está más allá de cualquier dualismo y, aparte de ser una relación compleja entre bíos (vida organizada, humana), zoé (vida natural, animal) y techné (técnica, tecnología), se muestra en toda su capacidad para construir nuevas formas de vida desde lo profundo del código genético, en donde es factible que, desde las corporalidades, en una apuesta estética y ética, sea "precisamente nuestra naturaleza textual lo que puede hacernos libres" (Aguilar, 2008, p.23). Así mismo, en la concepción de pensamiento crítico, la propuesta conceptual se ampara en la noción de crítica como actitud límite expresada por Foucault (2018) y la conexión entre la posibilidad de hacer un ejercicio crítico y deconstruir desde la experimentación planteada por Braidotti (2015), Haraway (1991) y otros. De igual modo, la propuesta conceptual se ampara en la idea de pragmática de Deleuze y Guattari (2015), la cual se distancia de la tradición lingüística para ubicarse como elemento analítico que analiza los agenciamientos que movilizan las enunciaciones y la configuración de regimenes de signos, que para este caso son aquellos ligados al código genético entendido como texto biológico y cultural.

Sin embargo, esta formulación conceptual no puede ser únicamente una concepción de tipo abstracto, sino que, al integrarse en el ámbito educativo, evidencia su aplicabilidad y, como ya se ha señalado, la posibilidad de integrar críticamente las ciencias naturales y los estudios sociales. Esto puesto que el estudio del código genético y sus modificaciones, al llevarse al plano educativo demanda la configuración de una serie de estrategias que permitan hacer visible una concepción de vida diferente pero también poder contar con las herramientas analíticas para acercarse a las tecnologías contemporáneas y comprenderlas, sin dejar de lado la tarea de conocer ese sí mismo que se entreteje con los códigos, las cifras y los datos que configuran el ADN. Por ello, la educación en la perspectiva de la investigación se entendió como convergencia, en otras palabras, como escenario de interacción y diálogo entre diversos métodos y epistemes, que, al lado de responder a la invitación de Wallerstein (1996) a generar ciencias multilingües, también se convierte en espacio de controversia y debate para poder generar los acercamientos críticos necesarios frente a los avances de la digitalización de la vida y los interrogantes que puede generar en diversos espacios de la sociedad y la cultura. De este modo, la educación, como el arte, le apuesta a una concepción según la cual hace crítica desde la diversidad pero también desde la creación, desde el análisis y la apertura, 
pero sobre todo desde el entendimiento profundo de que el análisis de la digitalización de la existencia en tiempos como los actuales exige de una pedagogía en la que las ciencias dialoguen e interactúen y al mismo tiempo estén en capacidad de impulsar el pensamiento crítico como acción creativa, analítica $y$, en última instancia ética y política, una educación para esas nuevas ciudadanías en el universo de lo molecular.

Metodológicamente hablando, esta apuesta conceptual se desarrolló a partir de la construcción de un trabajo académico de reflexión en clave de Investigación Acción Educativa, basada en el modelo de Elliot (2000) y con la concepción del trabajo con docentes en un proceso de espiral de acción - reflexión. Para ello, el trabajo en campo estuvo establecido a partir del ejercicio de reflexión con un grupo de 15 profesores de diferentes áreas con quienes se elaboró un diseño pedagógico inspirado en la interconexión de varios diseños provenientes de la pedagogía por proyectos, la pedagogía activa, la enseñanza para la comprensión, el aprendizaje significativo y la propuesta del pensamiento complejo, las cuales se organizaron bajo una lógica de acción en el aula que pasó por el conocimiento de las particularidades de los contextos latinoamericanos y las oportunidades de reflexión tecnológica que ofrecen, teniendo como punto de referencia un ejercicio crítico acerca de la digitalización de la vida. En el proceso de investigación, como ya se ha señalado, se trabajó el pilotaje y desarrollo de la propuesta mediante un taller con educadores en la ciudad de Cajamarca en Perú, de manera que fuese posible diseñar diferentes acciones en las que la relación cuerpo - texto - tecnología no se convirtiera en un elemento distante de los ámbitos educativos sino una parte fundamental para pensar procesos y acciones para la reflexión crítica sobre el desarrollo tecnológico actual y las formas de asumir una postura reflexiva frente a sus implicaciones en las sociedades contemporáneas y sus estatutos científicos y culturales. En todos los casos se partió de la idea de una escuela abierta y multidisciplinar en la que la corporalidad, las artes y el lenguaje son los puntos de partida para enfrentar una problematización tan inquietante como la que implica el código genético y su papel definitivo en el horizonte tecnocientífico de la digitalización contemporánea.

\section{HACIA UNA PEDAGOGÍA DE LA VIDA DIGITALIZADA Y LA TEXTUALIDAD DE LA CORPORALIDAD COMO CONVERGENCIA CRÍTICA ENTRE LENGUAJE, CIENCIA, ESTÉTICA Y ÉTICA.}

El proceso de trabajo pedagógico adelantado con los docentes consistió en revisar los elementos a considerar en la construcción de una especie de caja de herramientas para asumir críticamente los procesos biotecnológicos en la escuela, para lo que se recurrió, del mismo modo que en la integración de saberes en el orden conceptual y disciplinar, a una apuesta de convergencia entre modelos pedagógicos y herramientas metodológicas de tipo didáctico y critico - creativo. Así, el trabajo educativo se convirtió en un ejercicio establecido desde una serie de principios básicos y procesos a considerar para poder llevar a los espacios escolares a enfrentar los nuevos horizontes tecnológicos y conceptualizaciones resultantes del avance de la digitalización de la vida, pero sin dejar de lado las condiciones propias de los contextos tanto rurales como urbanos por los cuales pasa la experiencia educativa. Así, la estrategia trabajada resultó no solo en un elemento de tipo inter y transdisciplinar, sino también de orden multisituado, de manera que pudiese llevarse tanto a diversos escenarios en los que las tecnologías digitales aún no han llegado con toda la potencia de los procesos de edición de código genético (pero que, como se vio en el taller se afectan directamente por este tipo de procesos), como a espacios urbanos en los que la digitalización se ha convertido en parte 
de la cotidianidad de los sujetos y por tanto un objeto de reflexión más allá del uso instrumental de las herramientas digitales.

En el proceso desarrollado y trabajado con el colectivo de maestros, se tuvieron como punto de partida cinco condiciones fundamentales: la necesidad de entender que el giro epistemológico de la vida como información algorítmica exige, por su complejidad, de la interacción entre disciplinas; el entendimiento de la existencia como una cuestión biopragmática, esto es, el hecho de que se vive desde las prácticas, con la interacción de múltiples códigos y sin la preponderancia de uno en particular, sea genético o digital; la comprensión de la matriz ontológica del cuerpo como texto, lo que permite dar cuenta de una visión de la corporalidad como posibilidad de escritura y por tanto, de creación; el conocimiento preciso de las tecnologías actuales y particularmente de ese panorama que ofrecen las tecnociencias y la edición genética y sus implicaciones sociales y culturales; $y$, por último, la conciencia clara acerca de la necesidad de un empoderamiento acerca de eso que somos en la relación cuerpo - texto - tecnología. Cinco elementos que permitieron a los docentes llevar a cabo un proceso de reflexión acerca de las posibilidades para poner en acción en la escuela la reflexión sobre la digitalización de la vida más allá de una dimensión solamente teorética o informativa.

En cuanto a la primera de estas cuestiones, la de la apertura disciplinar, la interacción con docentes permitió hacer visible la dificultad que implica la ruptura del modelo de división de saberes en los entornos educativos pero también la importancia que ello tiene para el trabajo con las modificaciones epistemológicas y ontológicas ligadas al desarrollo biotecnológico. Las tecnologías de la vida contemporánea no pueden abordarse en los espacios escolares si no se hace con la interacción entre diversos saberes para poder entender la profundidad y dimensión de los cambios de la contemporaneidad y que pasa por los esquemas de las ciencias naturales, las tecnologías propiamente dichas y la ciencias sociales y humanas. Por ello, se requiere de la interpretación crítica de la matemática para analizar los algoritmos, de la informática para comprender sus aplicaciones, de la biología, la física y la química para leer las modificaciones moleculares, pero también de la educación física y las artes para interpretar los movimientos de los cuerpos y de las ciencias del lenguaje, la filosofía y los estudios de la sociedad para pensar las implicaciones culturales, ontológicas y éticas de los desarrollos tecnológicos. $Y$ esas interacciones no se limitan únicamente a los grados superiores, sino que son una exigencia para que, incluso desde las primeras edades en las que la interacción con la tecnología pasan por el uso del celular, se generen las condiciones para pensar las modificaciones que esto realiza sobre la vida, sus ritmos y posibilidades.

En lo que atañe a una visión biopragmática de la vida, se evidenció que si bien se entiende el concepto en términos generales, se hace un tanto más difuso cuando se mueve hacia las condiciones más precisas de los datos, las cifras y la biología; sin embargo, tal cual se evidenció en el taller, solamente al moverse más allá del carácter estático de los signos es posible reconocer esos otros elementos que modifican no solo la vida, sino también la corporalidad y la subjetividad. La vida no puede entenderse, en el contexto de la digitalización y la tecnología meramente como secuencias de código, sino, como la ha planteado Rose, si (2012), "“la vida en sí se resiste a su reformulación en términos vinculados con la información" (p. 116), es preciso, como efecto de la interacción entre saberes, abrir la comprensión de la vida hacia la multiplicidad e interconexión. Los algoritmos y las tecnologías de hoy pueden editar los genomas y hacer recortes precisos en el ADN, pero la misma molécula de la vida no existe independientemente de la naturaleza o de la cultura, por ello el análisis no puede limitarse a 
la vida como sistema de signos, sino ante todo como un espacio social, en el que se entrecruzan los signos biológicos con los símbolos culturales en una mediación e interacción permanente que configura a nivel interno y externo eso que somos.

En lo que se refiere a la idea del cuerpo como texto, la perspectiva fue aun más clara y contundente, toda vez que emergió la concepción de una multiplicidad de niveles y textualidades, expresados desde la epidermis hasta los niveles de configuración molecular. La corporalidad hoy es un asunto de vital protagonismo en los sujetos y es preciso que no solo se exprese desde su plano material, sino que se entienda en la escuela que las corporalidades están profundamente conectadas con la subjetividad y el pensamiento. El cuerpo expresa lo que somos a través de la piel, pero también es lo que somos en sus estructuras más profundas y superficiales. Por ello es preciso que en la escuela se configure una relación de comprensión y creación con los cuerpos, susceptible de hacer visible su capacidad, pues como señala Negri (2016), en los contextos contemporáneos "icuánto puede el cuerpo!... ha dejado de ser una consolación y asimismo de representar cualquier tipo de polaridad trascendente o trascendental... Es vida, es incorporación, es trabajo" y por tanto es necesaria una educación en la que si bien la tecnología se reconoce en su incorporación a la vida, también es fundamental para la docencia recuperar la textualidad de la corporalidad, la que se escribe con su conocimiento, su cuidado y la capacidad de hacer del cuerpo un territorio de sentido y oportunidad para la crítica y la construcción de la subjetividad.

Frente al conocimiento tecnológico, aparecieron algunas dificultades de apropiación y acercamiento, pero, en todo caso, resultó evidente la necesidad de comprensión e información frente a los desarrollos tecnológicos contemporáneos y sus conexiones con diversos niveles de la cotidianidad. Para los docentes que asumen el reto de la digitalización en su conexión actual con la existencia es necesario estar al día y al tanto con los descubrimientos y avances tecnológicos, de manera que sea factible mantener una actitud analítica y crítica, capaz de cuestionar las diversas implicaciones tecnológicas y en sintonía con los debates profundos de espacios como los de la bioética pero también de los modos en los que cualquier experimentación puede afectar las condiciones de vida tanto globales como locales. Se trata de ir más allá de la revolución tecnológica para estar en actitud crítica frente a ella, sin tecnofilias ni tecnofobias, sino desde el reconocimiento del modo en que cada avance va modificando no solo la vida y la corporalidad desde una mera exterioridad, sino desde la más profunda interioridad.

En el caso del empoderamiento, este elemento terminó por convertirse también en una cuestión fundamental y decisiva no solo para el docente que se enfrenta al reto de la digitalización de la vida, sino también para el caso del trabajo con los estudiantes. Estudiar el cuerpo y la existencia en tiempos de su digitalización a partir del reconocimiento de sus textualidades y su naturaleza práctica en tanto que lenguajes en movimiento y conectados con el universo de lo social y lo cultural, genera en el campo educativo la necesidad de llevar a que la práctica en aula permita no solo un reconocimiento sino mejor, las condiciones para hacerse conscientes de la necesidad de empoderarse de lo que hoy implica la corporalidad en su naturaleza como texto. De modo que si, en el siglo XXI, como lo plantea Harari (2018) "los datos eclipsarán a la vez la tierra y la maquinaria como los bienes más importantes, y la política será una lucha para controlar el flujo de datos" (p. 100), ética y políticamente el acto más apremiante desde la escuela es justamente construir los caminos para que el empoderamiento del cuerpo sea a la vez el empoderamiento de las cifras, códigos e interacciones que constituyen eso que somos y 
que antes que estar en entramados de servidores y diseño, es algo que pertenece como posesión preciada a los sujetos siendo a la vez el espacio fundamental para el desarrollo de su libertad.

Pero no solamente se tuvo en cuenta una serie de condiciones para la reflexión con los docentes a la hora de desarrollar procesos educativos en el marco de las relaciones entre cuerpo, texto y tecnología para asumir críticamente los procesos de digitalización de la vida; también aparecieron elementos propiamente pedagógicos a considerar: la necesidad de una integración de metodologías y modelos en la práctica didáctica, que permitieran ir de la actividad a la reflexividad pasando por la significatividad de los elementos trabajados en las clases; el impulso del pensamiento crítico como cuestión necesaria para asumir la complejidad de las problematizaciones implicadas en la relación cuerpo - texto - tecnología a partir de un ejercicio de lectura e interconexión entre los desarrollos de la digitalización y los contextos situados; la necesidad de una integración entre la estética como proceso de la imaginación creadora resultante del trabajo crítico, y la ética como ejercicio de autorreflexión y de mirada acerca de las responsabilidades propias del contexto de la biotecnología. Una serie de elementos que configuran en cierto modo la hoja de ruta para el trabajo en el aula y la posibilidad de llevar al ejercicio estético y ético a ser incluso un ejercicio investigativo y por tanto, profundamente político.

En el caso de la integración de métodos y diseños pedagógicos, lo que se hizo visible es el hecho de que para poder llevar a cabo el trabajo académico es necesario ofrecer una diversidad de las prácticas que despierte el amor por el conocimiento y la curiosidad y si bien un tema como el de los desarrollos tecnológicos deslumbra con sus altos grados de avance, no deja de exigir un trabajo didáctico de interacción entre modelos y herramientas, más aún cuando, como se ha planteado, se trata de un ejercicio de convergencia entre disciplinas. La escuela contemporánea y más aún la escuela latinoamericana con su profunda diversidad, demanda de la combinación de modelos y estrategias de enseñanza para hacer del conocimiento un viaje y una aventura. Se trata de involucrar diferentes estrategias y acciones en el aula para hacerla un cúmulo de experiencias que no se reducen a un manual de procedimientos, sino que expresan el hecho de entender el aprendizaje como un ejercicio en constante transformación, que pasa de los juegos y la discusión creativa a la conexión de los saberes con la cotidianidad de los estudiantes, sin dejar de lado las relaciones inter y transdisciplinares y la apertura a la creación. Como lo señalaban los docentes, en la práctica, no hay un solo modelo y cuando se trata de tecnologías tan complejas, es necesario emplear todas las herramientas y referentes, desde los relatos cinematográficos o de ciencia ficción hasta la mirada bajo el microscopio con absoluto rigor, pasando por las dinámicas y las discusiones, educando al mismo tiempo en todas las habilidades y competencias que se ponen en acción cuando la ciencia se abre a múltiples aristas y miradas en términos de comprensión y problematización.

En lo que refiere al trabajo con el pensamiento crítico, este implica la consolidación del trabajo pedagógico como un ejercicio que estimula la capacidad de plantear preguntas y de interrogar los diferentes elementos bajos los cuales se organiza el contexto biotecnológico. Se trata de partir de la realidad más cercana para cuestionar los modos en los que se encuentra estudiada, contemplada y analizada por la tecnología, y al mismo tiempo tener la capacidad de cuestionar profundamente las implicaciones de los desarrollos contemporáneos desde los esquemas de las diversas disciplinas y a partir de los cruces conceptuales y metodológicos entre ellas. ¿cómo le afectan estos elementos a lo que soy?, ¿qué tanto sé acerca de cómo se mueven mis datos en la red?, ¿Qué tan consciente estoy de las textualidades que se anidan en los 
entresijos de mi corporalidad?, ¿cómo se afecta el medioambiente y la condición humana con la modificación genética?, ¿cuáles serían los límites para las tecnologías genómicas y qué brechas sociales y problemáticas culturales generaría su implementación?, serían preguntas fundamentales a promover en los contextos escolares y que permitirían tanto la actualización de las reflexiones tecnológicas como la superación de ver la tecnología como un elemento instrumental para comprenderla en su conexión con la cotidianidad. Así mismo, el impulso de una cultura escolar del cuestionamiento permitiría consolidar espacios para hacer de la escuela un escenario para el impulso de la investigación reflexiva y de la crítica como una tarea que no se construye desde afirmaciones sino desde cuestionamientos y para ello el contexto actual de avance biotecnológico más que ofrecer cajas negras o misterios, lo que convoca es a la discusión y la polémica.

En el cruce entre estética y ética, por otro lado, aparece un trabajo necesariamente de creación y reflexión en el ejercicio analítico y de creación que puedan realizar los estudiantes. No se puede pensar en que el límite sea la no tenencia de herramientas, pues en el contexto educativo nada puede restringir la imaginación y hoy, en tiempos en los que pareciera una especie de privilegio el detenimiento, la contemplación y el acto de soñar, los contextos educativos tienen la necesidad de generar las condiciones para que imaginar sea el punto de partida para pensar y actuar sobre la tecnología. Esto pues si, como en el caso de contextos rurales o de escasa conectividad o laboratorios, no se cuenta con los avances directamente al alcance de la mano, de modo que, como suele ocurrir en nuestras latitudes, "Latinos don't have real access to new technologies, we imagine the access. All we have is our political imagination and our humor to interject into the conversation" (Gómez Peña, 2005, p. 250). En otras palabras, hacer del acto imaginativo un ejercicio crítico, como lo ha hecho la literatura y el cine. Pero si es crítica, es también ética y política, posibilidad de no solamente imaginar el panorama tecnológico sino también qué hacer con ello, qué decisiones tomar y cómo convertir la apropiación del cuerpo y de la vida en un acto que combina el conocimiento de sí a nivel molecular en el cuidado y empoderamiento de sí. Una estética que es una ética incluso sin la presencia tecnológica y que se expresa mediante el performance, la creación literaria o el debate y que, cuando se cuenta con los recursos puede también generar procesos analíticos y creativos desde la escuela en los que la robótica, por ejemplo, no sea solo armar el robot, sino también estar en capacidad de pensar en sus implicaciones más allá de su presencia, en esa condición de equilibrio dinámico entre sujeto y objeto que emerge con el desarrollo de las tecnologías de la vida.

La ruta delineada con los docentes, en consecuencia, estaría dada por un trabajo que va de la información a la problematización y finaliza con la creación, todo ello bajo la batuta de la vida concebida como algoritmo y el cuerpo como textualidad. La estrategia no es otra que la de llevar el conocimiento acerca de la potencia tecnológica sobre la vida, incluso en el código genético y su modificación al escenario escolar en un esquema de trabajo que no sea únicamente informativo, sino ante todo crítico y creativo. Para ello el proceso pasa por la interacción mediante diversos recursos con los contextos creados por el desarrollo tecnológico y las maneras en las que se ha transformado eso que entendemos por vida, cuerpo y humanidad en las sociedades contemporáneas. Esto se realiza mediante el diálogo entre diversas disciplinas y su adaptación a las edades y condiciones de los estudiantes, lo que implica en los docentes conocimiento de sus contextos, al lado del saber acerca de los avances tecnológicos, para poder trazar relaciones significativas desde la cotidianidad. Posteriormente, la tarea consiste en generar espacios para el debate y la imaginación, para la 
estética y la ética reflexiva desde el proceso de planteamiento de posibilidades de apropiación de la existencia y la corporalidad como textualidades, para lo cual el camino puede ser desde el trazado de secuencias didácticas hasta proyectos de aula, teniéndose siempre como bandera pensar en la meta de llevar el saber sobre la vida digitalizada a la práctica, esto es, a la configuración de una reflexión que puede convertirse en una obra artística que sintetiza y moviliza la reflexión mediante la potencia del teatro, la instalación o la creación literaria, que no puede dejar de interconectarse con los saberes de las ciencias naturales y sociales que encuentran en la reflexión crítica su punto de convergencia. Una serie de acciones que no se convierten en una receta, sino mejor en una advertencia metodológica, en la que siempre se ha de tener presente que, frente al panorama cambiante e inquietante de la sociedad, es preciso, en tiempos de la biotecnología, no perder de vista que su conocimiento en el aula no puede dejar de estar conectado con la crítica, la interconexión entre las disciplinas y la capacidad de enlazar la estética y la ética como elementos para problematizar el desarrollo tecnológico y su conexión con la sociedad, la cultura y la misma vida.

Bajo estas perspectivas, los docentes también identificaron una serie de debilidades a considerar a la hora de llevar este tipo de procesos al ámbito educativo y que se acercan directamente a diferentes problemáticas encontradas a la hora de trabajar con tecnología en el ámbito escolar. En primer caso está la necesidad de renovar los diseños curriculares y adaptarlos a los contextos actuales y sus exigencias, de manera que sea factible establecer un diálogo entre lo que se considera como ese saber necesario y obligatorio y las maneras en las que se moviliza en los contextos digitales actuales. Esto implica un ejercicio crítico - reflexivo por parte de la comunidad educativa y la construcción de espacios para el análisis y la investigación en los entornos escolares que conlleve a una renovación de ese espíritu que caracteriza al docente investigador. El aula, en consecuencia, en tiempos de la digitalización de la vida debe convertirse en laboratorio y el maestro devenir en analista, artista, guía y creador, un sujeto que, atravesado por la dinámica siempre en constante movimiento de la investigación, convoca, guía y lidera procesos reflexivos permanentes, que interrogan la tecnología y la existencia y que ante los cambios epistemológicos contemporáneos responde desde la creatividad y la posibilidad de establecer comunidades de análisis con otros investigadores y disciplinas sin dejar de lado la llama incesante del cuestionamiento y la crítica creativa como faros para asumir el reto que implican la condiciones actuales de las tecnologías de la existencia. Una tarea, que, como todo ejercicio educativo implica de compromiso y paciencia, de esa actitud del educador para repensarse en el universo abierto de sus prácticas y, ante la tecnología avanzada, en la tarea de consolidar esa voluntad crítica que se convierte en la posibilidad de ejercicio ético, crítico y político para las próximas generaciones.

\section{CONCLUSIONES: EDUCAR EN LA IMAGINACIÓN Y LA ACCIÓN; LA BIOPRAGMÁTICA Y LA POÉTICA DE LA EXISTENCIA}

Las discusiones con los docentes, pero también la reflexión teórica y el análisis de las prácticas del bioarte y el desarrollo biotecnológico, fuentes de la investigación presentada en este artículo, llevaron a una serie de conclusiones en el orden educativo en las que se hace visible la profunda necesidad que existe en los contextos contemporáneos de repensar la educación no solamente para sintonizarla con los desarrollos tecnológicos de la digitalización de la vida, sino también para brindar los elementos necesarios para generar en la escuela espacios reflexivos y crítico creativos acerca de eso que somos y estamos siendo en una época de cambios y transformaciones como la actual. Se configuran 
las siguientes ideas para considerar en los ambientes y entornos educativos a la hora de enfrentar el reto de educar en tiempos de la digitalización de la vida.

En primer lugar, es preciso actualizar los debates ante las condiciones y transformaciones generadas con el avance de las tecnologías y la digitalización. Es tiempo de asumir que las tecnologías de hoy ya no son exclusivamente herramientas externas a los sujetos, sino que están presentes en su cotidianidad, tanto en las pantallas con las que se interactúa en el día a día como en el algoritmo que dirige las búsquedas rutas y trayectorias y en las biotecnologías para las que el $A D N$ es el punto de partida y no un misterio. Por lo tanto, en todas las áreas del conocimiento a nivel educativo es necesario entrar en la conversación de los avances tecnológicos y sus implicaciones antes de que los desarrollos digitales y tecnocientíficos rebasen a los análisis disponibles y se caiga en el riesgo de no entender las tecnologías y terminar curiosamente convertidos en sus consumidores de manera irreflexiva e instrumental. Los avances tecnológicos de hoy, como se ha señalado en este artículo, implican cambios ontológicos y epistemológicos, por lo que la escuela debe convertirse en un espacio en sintonía con estas transformaciones y con la capacidad de mirar hacia el porvenir desde el presente en ese ejercicio crítico que implica reflexionar las implicaciones y problematizaciones que se generan cuando la tecnología, como hoy, tiene la posibilidad de controlar y diseñar la vida.

Una segunda cuestión a considerar se refiere a la necesidad cada vez más apremiante de rescatar el valor del cuerpo y el lenguaje como elementos para reflexionar en la escuela. Esto porque si la tecnología más avanzada se inspira justamente en la textualidad de los cuerpos y su posibilidad de apropiación para el desarrollo de la vida y la inteligencia artificial o el mejoramiento y modificación de la existencia y de lo humano, el contexto educativo no puede dejar de lado ese factor decisivo que es el carácter sígnico y textual de la corporalidad. Por el contrario, junto a los estudios artísticos, científicos, sociales y culturales sobre el cuerpo, es preciso generar condiciones en la escuela para que los sujetos puedan apropiarse y entender las múltiples dimensiones en las que confluyen subjetividad y corporalidad $y$ con mayor contundencia en el contexto de los avances y desarrollos tecnológicos en los que se hace visible que la potencia de los cuerpos está en su capacidad de significar, de ser signos en acción e interconexión. Un trabajo que, como lo requieren los escenarios actuales, no puede hacerse desde una sola disciplina, sino entendiendo el cuerpo como un elemento analítico de tipo transversal.

Como tercer punto a considerar a manera de conclusión aparece la necesidad de tomar a la vida como un objeto de reflexión necesario para ser trabajado en los entornos educativos. Es momento de romper esa extraña brecha que pareciera separar a la escuela de la cotidianidad y por ello, como ocurre con el cuerpo, la existencia tiene que ser un tema central para la reflexión educativa y ello no puede hacerse únicamente desde abstracciones y conceptos, sino, en esencia, desde las prácticas y, en el contexto tecnológico, desde esos modos en los que vivir hoy es algo que no puede separarse de la digitalización incluso sin la presencia de tecnología. Por ello es preciso llevar al escenario educativo la reflexión seria y crítica sobre las conexiones entre los modos de existencia y los desarrollos tecnológicos, tanto en las maneras en las que es visible en escenarios como los de las pantallas como en aquellos en los que se teje de modo invisible como ocurre con los procesos genéticos y biotecnológicos, de manera que se comprenda, en el fondo, que todos los saberes terminan por afectar la forma en la que se vive y a la vida misma en su conjunto más allá del bíos en el zoé de la naturaleza. 
Ahora bien, en un cuarto lugar, como conclusión aparece la recuperación del papel de la imaginación en la tarea de construcción de un pensamiento crítico en tiempos de desarrollo tecnológico. Como se ha señalado, la excusa no puede ser no contar con las herramientas, pues la máquina de la creatividad puede pensarlas, como lo ha hecho la literatura, sin su presencia $\mathrm{y}$, con la potencia imaginativa problematizar esas implicaciones de la digitalización de la existencia. Así, si la crítica es cuestionamiento permanente e impulso a la investigación, el punto de partida ha de radicar en el acto de imaginar para reflexionar, de plantear esos mundos posibles que incluso hoy ya son reales pero que no dejan de generar inquietudes que es necesario llevar a las realidades escolares en un ejercicio de apertura a sincronizarse con los debates tecnológicos actuales no desde una mera reproducción de información, sino desde esa posibilidad de interrogación que emerge con el trabajo creativo que implica reflexionar los avances de la biotecnología y sus implicaciones en las formas de vivir, ser y actuar de los sujetos en la contemporaneidad. La imaginación así no solamente se ocupa de mundos ficcionales, sino que ellos son una invitación responsable a reflexionar y pensar acerca de la vida en el marco del avance actual de la tecnología.

El trabajo crítico creativo lleva como consecuencia a una quinta conclusión en la que aparece el hecho de concebir la ética como una poética basada en la relación entre crítica y creación en el ejercicio analítico sobre las tecnologías de la vida. No se trata entonces de una disciplina abstracta o de regulaciones, sino mejor, de una práctica que se realiza como una poesía de la existencia, un trabajo analítico en el que lo estético y lo ético se conjugan en tanto que la reflexión no es solo un ejercicio hacia un afuera, sino la propuesta de la construcción desde un adentro, esto es, desde la apropiación de la corporalidad como textualidad y de las interacciones de la misma con el contexto de la digitalización de la existencia. Así mismo es la concepción del ejercicio de debate crítico ante los marcos sociales y culturales del desarrollo tecnológico contemporáneo que pasa por imaginarlo y al mismo tiempo por construir las inquietudes y debates frente a las responsabilidades y compromisos de los sujetos en un nuevo horizonte en el que la vida no es solo mecánica y estructuras materiales sino también datos y algoritmos que demandan de una reflexión ética inaplazable y necesaria en la escuela, más allá de la abstracción de las normas, en la vivencia de las condiciones para una poética del vivir que entiende que si el cuerpo y la vida son textos, más que códigos son poema y poesía.

Este modo de realizar la interacción entre ética y estética pasa por un trabajo necesario que es consecuencia del ejercicio de llevar al escenario escolar la reflexión sobre la vida y el cuerpo en tiempos de la digitalización de la vida, dado que la apropiación de la que se ha hablado hasta el momento, realizada bajo la batuta de la crítica creativa y el desarrollo de procesos de convergencia entre disciplinas, implica en el fondo un trabajo profundo de conocimiento acerca de lo que somos y sobre todo lo que estamos siendo. Pero ese saber, que es a la vez una práctica libertaria, es también un ejercicio que conduce al cuidado, a la responsabilidad sobre eso que somos más allá del código, en la práctica cotidiana en la interacción entre cuerpo, texto y tecnología, en la que, definitivamente, "hoy es preciso que el cuidado de sí pase por el conocimiento de sí, de manera tal que desaparezca la tensión entre ambas instancias" (Rodríguez, 2017, p. 109). Un trabajo en el que el acto pedagógico pasa del saber a la actuación, del cuidado de sí al cuidado de los otros, a esa ética que, como la vida, se abre a la interacción entre los múltiples códigos que hoy configuran lo que se entiende por existencia y en donde esos otros son también esa vidas humanas y naturales que interactúan en un entorno emergente como 
el actual, en el que la episteme de la vida como información algorítmica, no solo ha hecho visible que seamos código, sino que esa codificación es la que permite que la realidad sea un continuum, una interconexión entre todas las existencias.

Así pues educar es, en tiempos como los actuales, pensar en condiciones para potenciar la crítica, la imaginación y la acción, la estética y la ética como prácticas más que como conceptualización. Se trata, en consecuencia, de un ejercicio de interacción y análisis de la vida y sus transformaciones que, por efecto de la tecnología, le han llevado de la información al algoritmo, de los datos a la interconexión. Por ello, se requiere de una transformación en los entornos educativos en la que se haga visible el modo en el que la existencia hoy está atravesada incluso desde el nivel molecular por la digitalización y que por ello mismo requiere para su análisis de un cambio conceptual en la textualidad de las corporalidades que se ubique en el entorno siempre abierto de las prácticas, en donde la vida se hace interactiva, no una determinación digital, sino una interrelación entre la naturaleza, el desarrollo tecnológico, la sociedad y la cultura. Una biopragmática que conduzca, por encima del inventario de tecnologías, técnicas y conceptos, a comprender que si el cuerpo es texto y la vida información algorítmica, el mejor camino para entender qué es eso que somos en tiempos de la digitalización, es construir los elementos para consolidar, desde el nivel molecular, las condiciones para hacer factible una poética de la existencia.

\section{REFERENCIAS BIBLIOGRAFICAS}

Agamben, G. (2017) El uso de los cuerpos. Adriana Hidalgo

Aguilar, T. (2008) Ontología Cyborg. Gedisa

Baudrillard, J. (2009) La sociedad de consumo. Sus mitos sus estructuras. Siglo XXI.

Bachelard, G. (1974) La formación del espíritu científico. Siglo XXI.

Bauman, Z. (2009) Modernidad líquida. Fondo de Cultura Económica.

Braidotti, R. (2015) Lo posthumano. Gedisa

Deleuze, G. y Guattari, F. (2015) Mil mesetas. Capitalismo y esquizofrenia. Pretextos.

Doudna, J. y Sternberg, S. (2017) A crack in creation. Vintage

Domenech, M. y Tirado, F.J. (1998) Sociología simétrica. Ensayos sobre ciencia, tecnología y sociedad. Gedisa

Elliot, J. (2000) La investigación acción en educación. Morata

Esposito, B. (2011) Bios. Biopolítica y filosofía. Amorrortu

Ferry, L. (2017) La revolución transhumanista. Alianza.

Foucault, M. (2018). ¿Qué es la crítica? seguido de la cultura de sí. Siglo XXI.

Gómez - Peña, G. (2005) EthnoTechno: Writings on Performance, Activism and Pedagogy. Routledge

Harari, Y. (2017). Homo Deus. Breve historia del mañana. Debate.

(2018) 21 lecciones para el siglo XXI. Debate.

Haraway, D. (1991). Ciencia, cyborgs y mujeres. La reinvención de la naturaleza. Cátedra. 
Hardt, M. y Negri, A. (2015) Imperio. Paidós.

Hoffmeyer, J.(2008) Biosemiotics. University of Scranton Press

Jameson, F. (2000) El giro cultural. Manantial.

Kac, E. (2010) Telepresencia y bioarte. CENDEAC.

Latour, B. (1987) Science in action: how to follow scientist and engineers thorough Society. The MIT Press

Lipovetsky, G. (2010) El imperio de lo efímero. Anagrama

López del Rincón, D. (2015) Bioarte: Arte y vida en la era de la biotecnología. Akal.

López - Pellisa, T. (2015) Patologías de la realidad virtual: cibercultura y ciencia ficción. Fondo de Cultura Económica

Lyotard, J.F. (1986) La condición postmoderna. Cátedra.

Mukherjee, S. (2017) El gen una historia personal. Debate.

Negri, T. (2016) Arte y multitud. Trotta.

Ong, W. (2009) Oralidad y escritura. Fondo de Cultura Económica

Paz, O. (1985) Los hijos del limo. Oveja Negra.

Piore, A. (2017) The body builders. Inside the science of the engineered human. Harper Collins.

Rifkin, J. (2009) El siglo de la biotecnología. Paidós

Rose, N. (2012) Políticas de la vida. UNIPE.

(2017) Nuestro cerebro, nuestro yo. En: Costa, F. y Rodríguez, P. (eds) La salud inalcanzable. Biopolítica molecular y medicalización de la vida cotidiana. (pp. 17-47). Eudeba
Rodríguez, P (2017) Biotecnologías del yo. En: Costa, F. y Rodríguez, P. (eds) La salud inalcanzable. Biopolítica molecular y medicalización de la vida cotidiana. (pp. 91113). Eudeba.

Sibilia, P. (2010) El hombre postorgánico. Cuerpo, subjetividad y tecnologías digitales. Fondo de Cultura Económica.

Spinoza, B. (2015). Ética demostrada según el orden geométrico. Fondo de Cultura Económica.

Wallerstein, I. (1996) Abrir las ciencias sociales. Siglo XXI. 